\title{
Brain Biogenic Monoamines in Relation to Brain Histopathology and Plasma Glutathione Shuttle in Rat after Exposure to Sea Anemone Gyrostoma helianthus Extract
}

\author{
Al-Hazmi MA, Gomma MN*, Waggas AS and Rawi SM
}

Faculty of Sciences and Arts, Khulias, King Abdulaziz University, Jeddah, Kingdom of Saudi Arabia

\begin{abstract}
The extract of sea anemone Gyrostoma helianthus (Cnidaria, Anthozoa) has been reported as a source of neuroactive compounds. The current study was designed to explore biogenic monoamine effects of sea anemone crude extract in relation to histopathological changes in brain areas and plasma glutathione shuttling. Mouse bioassays were used to determine the dose response curve and behavioral neurotoxicity. Loss of balance, opaque eyes, tonic convulsions, paralysis, muscle flexing, and exophthalmia were the major behavioral changes observed. The $\mathrm{LD}_{50}$ in mice was identified as $29 \mathrm{mg} / \mathrm{kg}$ body weight after IP injection, which is calculated to be $20.3 \mathrm{mg} / \mathrm{kg}$ body weight in rats using a conversion table.

Serotonin, dopamine, and norepinephrine were significantly increased in the cerebral cortex, cerebellum and pons plus medulla oblongata in rats in our 3-day study after a single IP injection of $1 / 2 L_{50}$ of the crude extract. The greatest increases in serotonin, dopamine, and norepinephrine were attained in the cerebral cortex. Cells examined in the cerebral cortex and hippocampus showed necrosis, pyknosis, focal gliosis, and congestion of cerebral blood vessels as well as focal cerebral and hippocampus hemorrhage. At the tested dose, the extract caused significant decreases in plasma glutathione and G-reductase, while G-transferase levels were increased.
\end{abstract}

Keywords: Gyrostoma helianthus; Sea anemone; Glutathione; Monoamines; Histopathology

\section{Introduction}

In the field of natural products, marine organisms have a rich heritage as therapeutic resources that have been exploited for effective and beneficial use against many human diseases [1], and some have been used to investigate novel drugs [2]. Sea anemones are one of the most ancient predatory marine animals. Pharmaceutical studies have demonstrated that the venom of several species of sea anemones produces different symptoms and modes of toxicity. Studies of inflammation and allergic reactions [3] hemolytic activities [4], immunomodulating activities [5], cardiotoxicity [6], and cytolytic effects [7] have all produced interesting outcomes. Moreover, the incidence of neurotoxicity reactions such as convulsions, paralysis, respiratory failure, cardiovascular reactions, and stroke $[6,8]$ is mostly recognized. Several studies have accumulated data attributing the effect to the diversity of polypeptide toxins [9]. It is increasingly recognized that many marine toxins interact with a large variety of excitable membranes, including myelinated and non-myelinated axons [10], neuronal cells [11] and nerve terminals [12]. Many have also shown activity with diverse receptors and voltage-gated ion channels [9]. Moreover, other investigators have reported that sea anemones' toxin provokes neurotransmitter release from synaptosomes, acts on different receptor structures in the membrane [13], and/or inhibits AChE activity [14].

Although the interest in marine toxins and venoms has increased during the last three to four decades, their mechanism of action at the monoamine level and the histological effect in different brain regions, which may solve unanswered questions related to their neurological effect, are still largely unknown and under debate. Therefore, the present work was designed to study the following: behavioral characteristics of toxic effects; the effect of an acute single dose of Gyrostoma helianthus ethanolic aqueous extracts on the cerebellum, cerebral hemisphere and pons and medulla monoamines; and plasma glutathione shuttling in relation to the histopathological changes in the cerebral hemisphere and hippocampal neurons.

\section{Materials and Methods}

\section{Sea anemone collection}

Specimens of sea anemone Gyrostoma heleanthus were collected from the west coast of the Red Sea at longitudes 380 o $45^{\prime}$ to $38 \mathrm{o}$ 50' E and from 210 51' to 210 52' N latitude near the Jeddah province of Saudi Arabia. Specimens were transferred to the laboratory in seawater.

\section{Preparation of the crude extract}

Live specimens were rapidly washed and then weighed. Absolute ethanol equal to the specimen weight $(1: 1 \mathrm{v} / \mathrm{w})$ was added with the anemone and mixed in a blender for 3 minutes. The blended material was centrifuged at $2570 \times \mathrm{g}$ for 10 minutes, and the 1 st supernatant was reserved for further steps. Pellets were extracted a second time with absolute ethanol (2nd supernatant) and a third extraction with 50\% aqueous ethanol (3rd supernatant). The three supernatants were added to each other and were then evaporated under reduced pressure at $40^{\circ} \mathrm{C}$ with a rotatory evaporator. Concentrated extracts were dried in a freeze dryer to obtain the final dried crude extract.

*Corresponding author: Mohamed Nasr Eldeen Gomaa, Prof., Head of Biology Department, Faculty of Sciences and Arts - Khulais, King Abdulaziz University, Jeddah, Saudi Arabia, Tel: 00966567755906; E-mail: mngomaa@gmail.com

Received October 21, 2014; Accepted November 17, 2014; Published November 26, 2014

Citation: Al-Hazmi MA, Gomma MN, Waggas AS, Rawi SM (2015) Brain Biogenic Monoamines in Relation to Brain Histopathology and Plasma Glutathione Shuttle in Rat after Exposure to Sea Anemone Gyrostoma helianthus Extract. J Bioequiv Availab 7: 005-011. doi:10.4172/jbb.1000208

Copyright: (C) $2015 \mathrm{Al}-\mathrm{Hazmi} \mathrm{MA}$, et al. This is an open-access article distributed under the terms of the Creative Commons Attribution License, which permits unrestricted use, distribution, and reproduction in any medium, provided the original author and source are credited. 
Citation: Al-Hazmi MA, Gomma MN, Waggas AS, Rawi SM (2015) Brain Biogenic Monoamines in Relation to Brain Histopathology and Plasma Glutathione Shuttle in Rat after Exposure to Sea Anemone Gyrostoma helianthus Extract. J Bioequiv Availab 7: 005-011. doi:10.4172/ jbb.1000208

\section{Animals}

Male albino mice (Mus musculus) with body weight of $20 \pm$ $2 \mathrm{~g}$ and rats (Rattus norvegicus) with body weight of $150-170 \mathrm{~g}$ were obtained from the animal house at the King Fahd Research at King Abdulaziz University. Laboratory Animal Welfare including environment, housing and management were conducted according to the recommendations for the proper care and use of laboratory animals by the American Association for Accreditation of Laboratory Animal Care (AAALAC) [15] and Al-Hazmi [16]. Rats were kept under good ventilation with 12 hour light and dark cycle, fed a stock diet, and allowed free access to drinking water.

\section{Mouse bioassay and neurobehavioral responses}

The mouse bioassay was conducted according to the method of AOAC [17]. Exactly $5 \mathrm{mg}$ of the crude extract was dissolved in $1 \mathrm{ml}$ of ultrapure water, and different dilutions were made to determine the dose response curve using Mouse Units. The median death time of 5 mice was used to calculate the Mouse Units of each dose. Neurobehavioral symptoms were observed during the assay after the IP injection.

\section{LD50 determination in mice}

Groups of six mice (18-22 g) each were IP injected with various concentrations of the crude extract (ranging from $5-50 \mathrm{mg} / \mathrm{kg}$ body weight). The toxicity was evaluated by determining 50 percent of the lethal dose (LD50) at $48 \mathrm{~h}$ according to the method of Litchfield and Wilcoxon [18]. Using the Paget and Barnes [19] conversion table, the LD50 for rats was calculated from the LD50 of mice.

\section{Biogenic monoamine determination}

Male rats were treated once by IP administration with $1 / 2$ LD50 of the lyophilized crude extract dissolved in ultrapure water. The animals were sacrificed at specific time intervals (1,2 and 3 days). The brain was rapidly and carefully removed and dissected on dry ice according to the method of Glowinski and Iversen [20] into cerebellum, pons plus medulla oblongata, and cerebral hemispheres. The dissected areas were wiped dry with filter paper, weighed and then homogenized in 10 volumes of $0.1 \mathrm{M}$ phosphate buffer ( $\mathrm{pH} 7.8$ ), using an ultrasonic homogenizer. The resulting homogenate was centrifuged at $10,000 \times \mathrm{g}$ for $60 \mathrm{~min}$ at $4^{\circ} \mathrm{C}$. The supernatant was collected and used to determine the levels of serotonin (5-HT), dopamine (DA) and norepinephrine (NE) according to the method of Udenfriend and Wyngaarden [21] as modified by Cliarlone [22]. The fluorescence activity of the tested samples was measured in a Jenway 6200 fluorometer.

\section{Determination of glutathione and related enzyme levels}

Following decapitation, blood was collected into clean heparinized centrifuge tubes and plasma was separated by centrifugation. Glutathione (GSH), glutathione S-transferase (GST) and glutathione reductase $(\mathrm{GR})$ were analyzed using the reagent kits purchased from Biodiagnostic.

\section{Histopathology}

Another group of animals was IP injected with the tested dose level. At the third day post-injection, the cerebral cortex and hippocampus were rapidly removed and placed in $10 \%$ buffered formalin for subsequent processing and histopathological evaluation.

\section{Statistical analysis}

One-way ANOVA was used to analyze the results of the biogenic monoamine determination, glutathione, and glutathione-related enzymes using statistical analysis SPSS v20, and LSD was used for mean separation [23].

\section{Results}

\section{Dose response curve}

The dose response curve (Figure 1) of ethanolic crude extract from the sea anemone Gyrostoma helianthus generated a threshold detected following the 2 mg.ml-1 injection with a response of 1.3 Mouse Units (MU). The curve plateaued at the $6 \mathrm{mg} \cdot \mathrm{ml}-1$ dose with a response of 3.8 MU. Increasing the dose to 7 and $8 \mathrm{mg} . \mathrm{ml}-1$ did not increase the response above 3.8 $\mathrm{MU}$. The dose response curve results were used to evaluate the neurological behavior response and to identify the dose that should be used in the LD50 determination.

\section{Neurobehavioral responses}

During the mouse bioassay study, the observed behavioral profile in mice after IP administration showed symptoms of convulsions, labored breathing, weakness of limbs, paralysis, walking imbalance, and occasional respiratory and body spasms. The most prominent feature at increasing doses was central nervous system excitation leading to severe convulsions and death.

\section{LD50 determination}

The acute toxicity study showed a sigmoidal dose-mortality relationship. Probit values (\% mortality) of the crude extract generated a straight line from which the LD50 was extrapolated. The LD50 value of Gyrostoma helianthus crude extract in mice was $29 \mathrm{mg} \cdot \mathrm{kg}^{-1}$ body weight after IP injection, which is calculated to be $20.3 \mathrm{mg} \cdot \mathrm{kg}^{-1}$ body weight in rats using the conversion table. To determine the effect of Gyrostoma helianthus crude extract on biogenic monoamines, calculated $1 / 2 \mathrm{LD}_{50}$ values for rats was used in all experiments. During this experiment, the behavioral changes previously observed in mice were also observed in rats.

\section{Effect on biogenic monoamines}

Dopamine (DA) levels: Gyrostoma helianthus crude extract

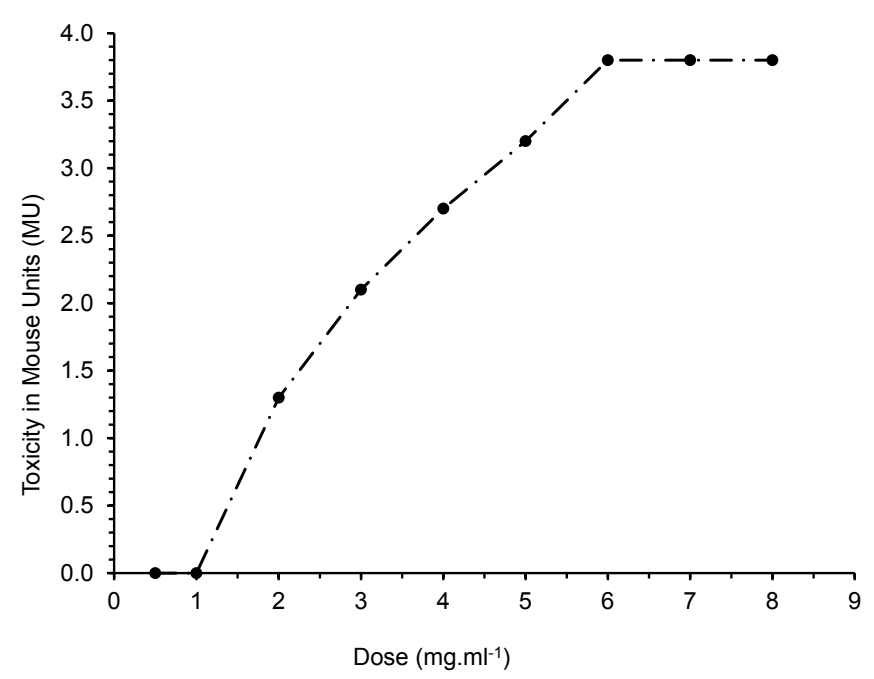

Figure 1: Dose response curve of the crude aqueous ethanolic extract of the sea anemone Gyrostoma helianthus after IP injection in $20 \pm 2 \mathrm{~g}$ male albino mice. 
Citation: Al-Hazmi MA, Gomma MN, Waggas AS, Rawi SM (2015) Brain Biogenic Monoamines in Relation to Brain Histopathology and Plasma Glutathione Shuttle in Rat after Exposure to Sea Anemone Gyrostoma helianthus Extract. J Bioequiv Availab 7: 005-011. doi:10.4172/ jbb.1000208

induced a highly significant increase in DA levels in all brain areas evaluated on the 1st day after injection compared to control rats (Figure 2). DA values increased $123 \%, 208 \%$ and $179 \%$ in the pons plus medulla, cerebral hemisphere and cerebellum, respectively. On the 2nd day after injection, DA values were decreased but still significantly higher than control values. DA levels were returned to normal by the 3rd day after injection in all brain areas evaluated, except the cerebral hemisphere, which showed the same elevated value as the 2 nd day following injection.

Norepinephrine (NE) levels: NE levels significantly increased in all brain areas compared to control (Figure 3). However, different profiles for the NE increase were observed for the different brain areas evaluated. The pons plus medulla and cerebral hemisphere displayed significant increases (154\% and $269 \%$, respectively) on the 1st day after injection with no significant change on the 2 nd and 3 rd days. A different NE profile was observed in the cerebellum where significant increases were elevated through the 3 days of the study, from $75 \%$ on the 1 st day to reaching $157 \%$ by the 3 rd day.

Serotonin (5-HT) levels: The same profile trend observed in NE levels was detected in the 5-HT profile (Figure 4). The 1st day increases for the pons plus medulla (50\%) and cerebral hemisphere (64\%) were not significantly changed on the $2^{\text {nd }}$ and $3^{\text {rd }}$ days. However, an increase in the cerebellum on the 1 st day $(130 \%)$ was followed by a continuous decrease on the $2^{\text {nd }}$ and $3^{\text {rd }}$ days but remained higher than control by $83 \%$ and $62 \%$, respectively.

Glutathione and oxidative enzymes: Gyrostoma helianthus crude extract significantly decreased the plasma concentration of glutathione (GSH). The maximum GSH reduction (29\%) was observed on the 3rd day after injection (Table 1). Glutathione S-transferase (GST) showed significantly higher values compared to control in the tested period with a maximum increase of $45 \%$ on the $3 \mathrm{rd}$ day after injection. However, the glutathione reductase (GR) values were significantly decreased compared to control with the maximum decrease (48\%) occurring on the 3rd day after injection (Table 1).

Histopathological observations: Histopathological changes in rat brain tissues showed that in contrast to the control group (Plate 1),

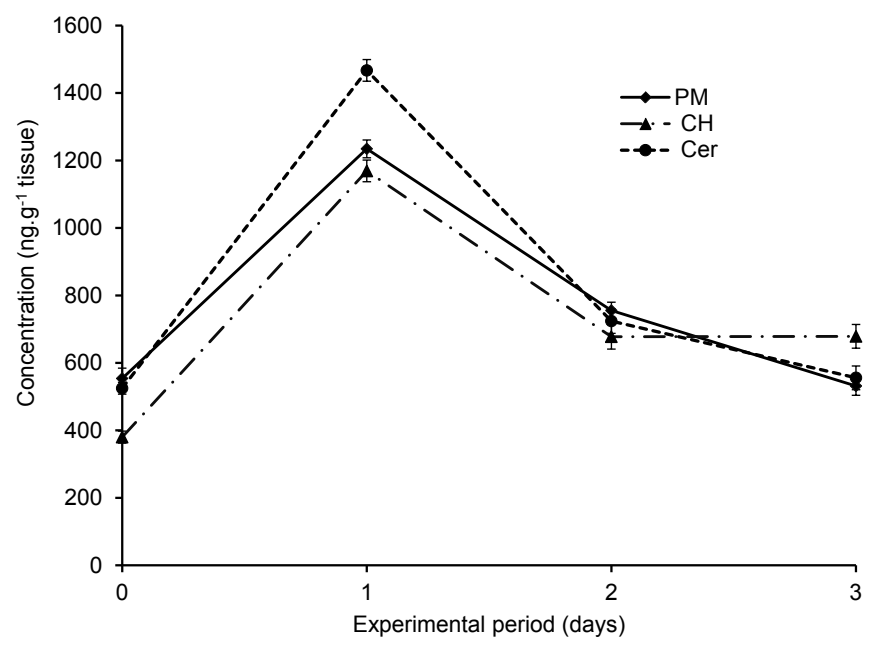

Figure 2: Dopamine concentration in pons plus medulla (PM), cerebral hemisphere $(\mathrm{CH})$, and cerebellum (Cer) of rat brain after IP injection with an acute single dose of Gyrostoma helianthus crude extract. Each point represents the mean $\pm \operatorname{SE}(n=6)$.

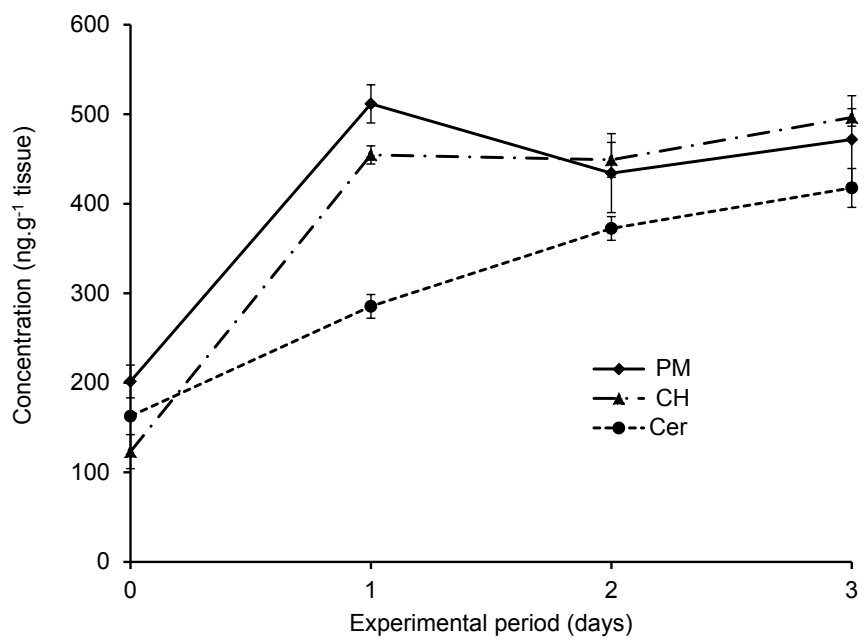

Figure 3: Norepinephrine concentration in pons plus medulla (PM), cerebral hemisphere $(\mathrm{CH})$, and cerebellum (Cer) of rat brain after IP injection with an acute single dose of Gyrostoma helianthus crude extract. Each point represents the mean \pm SE $(n=6)$

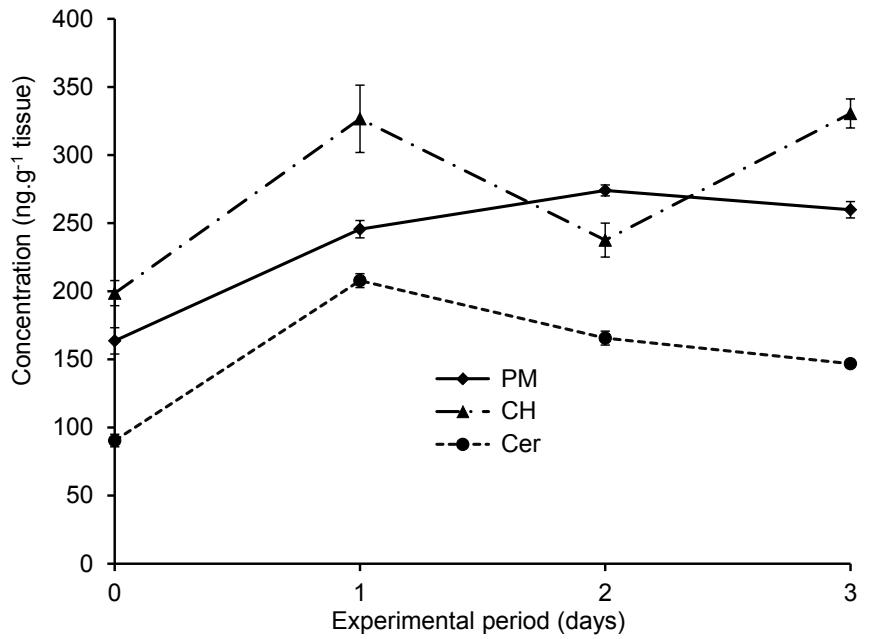

Figure 4: Serotonin concentration in pons plus medulla (PM), cerebral hemisphere $(\mathrm{CH})$, and cerebellum (Cer) of rat brain after IP injection with an acute single dose of Gyrostoma helianthus crude extract. Each point represents the mean $\pm S E(n=6)$.

\begin{tabular}{|c|c|c|c|}
\hline $\begin{array}{c}\text { Sampling Time after } \\
\text { injection } \\
\text { (Days) }\end{array}$ & $\begin{array}{c}\text { GSH } \\
(\mu \mathrm{mol} / \mathrm{L})\end{array}$ & $\begin{array}{c}\text { GST } \\
(\mathrm{IU} / \mathrm{dL})\end{array}$ & $\begin{array}{c}\text { GR } \\
(\mathrm{IU} / \mathrm{L})\end{array}$ \\
\hline 0 & $146.00 \pm 9.38^{\mathrm{a}}$ & $394.17 \pm 15.82^{\mathrm{b}}$ & $339.33 \pm 11.94^{\mathrm{a}}$ \\
\hline 1 & $112.63 \pm 2.95^{\mathrm{bc}}$ & $545.29 \pm 35.40^{\mathrm{a}}$ & $192.73 \pm 11.40^{\mathrm{b}}$ \\
\hline 2 & $126.13 \pm 7.85^{\mathrm{b}}$ & $540.98 \pm 21.00^{\mathrm{a}}$ & $187.40 \pm 9.86^{\mathrm{b}}$ \\
\hline 3 & $103.31 \pm 2.68^{\mathrm{c}}$ & $573.36 \pm 18.63^{\mathrm{a}}$ & $176.7 \pm 8.42^{\mathrm{b}}$ \\
\hline
\end{tabular}

Data are expressed as the mean \pm standard error $(n=6)$.

Means with the same symbol(s) are not significantly different. $P<0.001$

Table 1: Effects of IP injection of Gyrostoma helianthus crude extract at $1 / 2 L_{5}$ on serum glutathione (GSH), glutathione-S-transferase (GST) and glutathione reductase (GR) activity.

the cerebral cortex of treated animals exhibited cellular infiltration, atrophy, pyknosis, necrosis, neurology, congestion of cerebral blood vessels, cellular and perivascular edema as well as focal gliosis and focal 
Citation: Al-Hazmi MA, Gomma MN, Waggas AS, Rawi SM (2015) Brain Biogenic Monoamines in Relation to Brain Histopathology and Plasma Glutathione Shuttle in Rat after Exposure to Sea Anemone Gyrostoma helianthus Extract. J Bioequiv Availab 7: 005-011. doi:10.4172/ jbb.1000208

cerebral hemorrhage (Plates 2 and 3). Hippocampal neurons showed similar histopathological observations as the cerebral cortex. The most prominent observations of the examined sections were atrophy, pyknosis, shrunken cells and hemorrhage (Plates 5 and 6) compared to normal hippocampal cells (Plate 4).

\section{Discussion}

The investigation of new pharmacological tools and medicines through the study of action mechanisms of strong and highly selective interactions of some marine toxins with specific sites on excitable membranes has revealed a great deal about the physiology of affected tissues and systems [24]. As a result, the study of marine organisms as a source of biologically active compounds has led to the isolation of approximately 10,000 metabolites, many of which are components with pharmacodynamic properties [25]. Sea anemones contain mixtures of a variety of organic substances, including some potent toxins, permitting an improved understanding in the fields of pharmaceutical, neural, and biological sciences and allowing for the development of novel drugs [26].

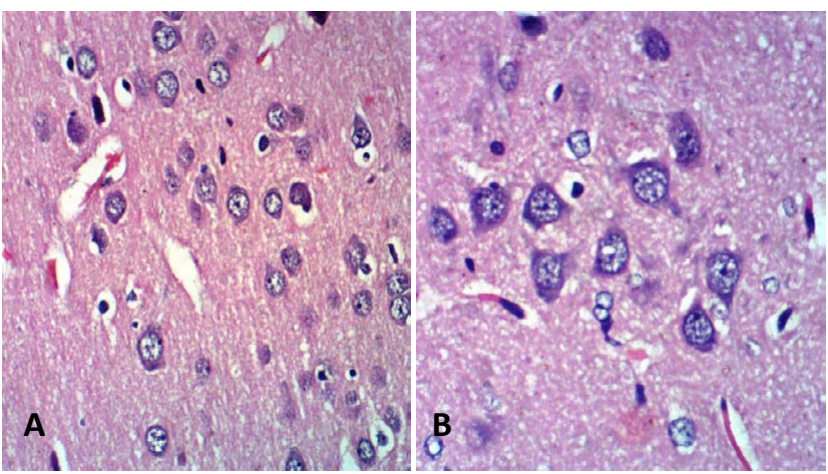

Plate 1: Photomicrographs of cortical cells of normal rat (A-B) [400X]

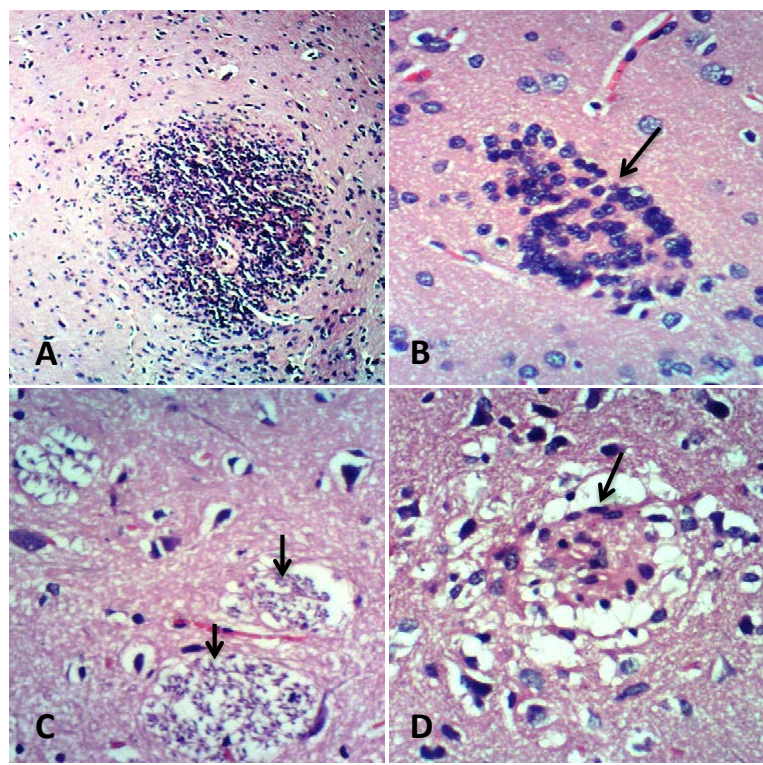

Plate 2: Effect of sea anemone crude extract on cortical neurons of a male albino rat showing focal cerebral necrosis infiltrated with glia cells $[A]$, focal gliosis (arrow) [B], demyelination of nerve fibers (arrows) [C], and focal cerebral necrosis (arrow) [D]. [400X].

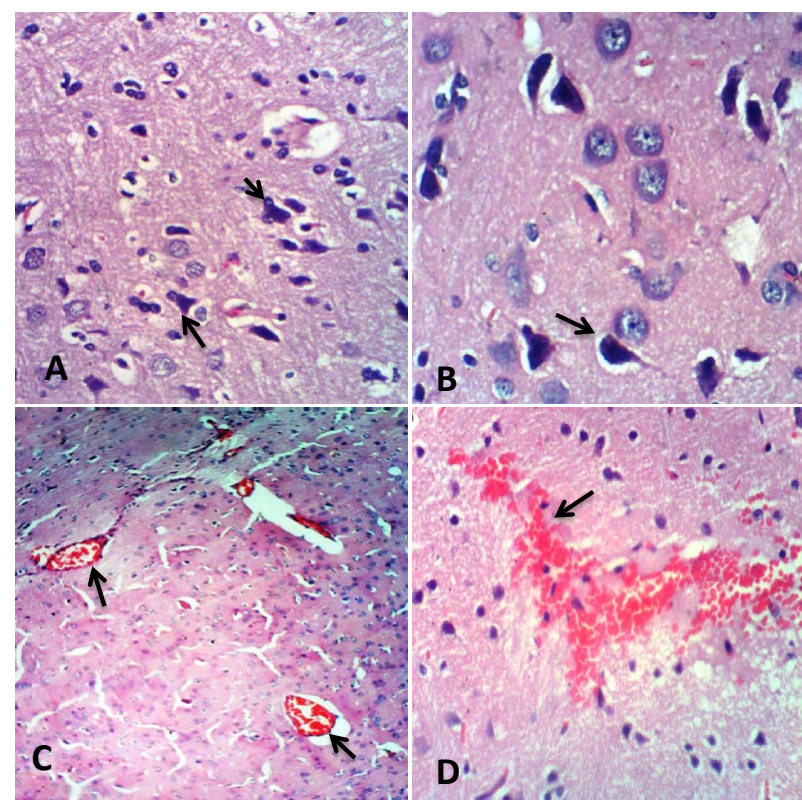

Plate 3: Effect of sea anemone Gyrostoma hileathus crude extract on cortical neurons in male albino mice showing necrosis of neurons and neurophagia (arrows) [A], necrosis and pyknosis (arrows) [B], congestion of cerebral blood vessels (arrows) $[C]$ and focal cerebral hemorrhage (arrow) [D]. [Figs A-C, 400X; Fig D, 100X]

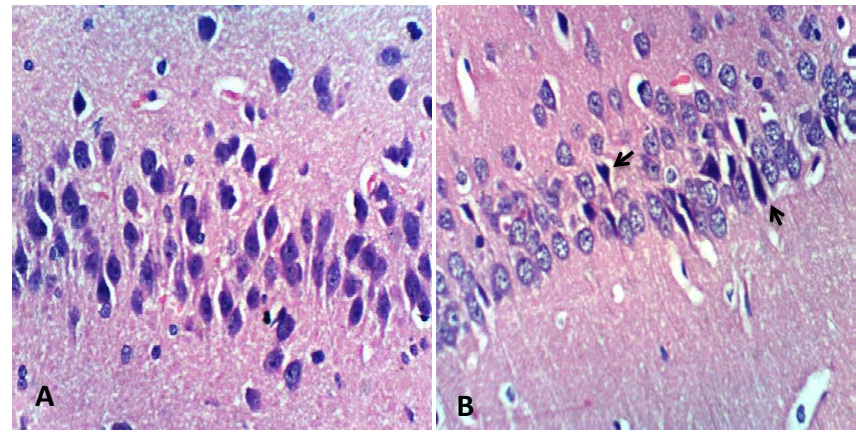

Plate 4: Normal histology of the Pyramidal cell layer of the Hippocampus in male albino mice $[\mathrm{A}]$. Rats treated with sea anemone Gyrostoma hileathus crude extract $[\mathrm{B}]$ showing pyknosis and atrophy of some pyramidal cells (arrow). [400X].

The ethanolic aqueous extract of the sea anemone Gyrostoma helianthus that showed lethality in mice in the current study was inconsistent with the findings of Mebs et al. [27], who stated that Gyrostoma helianthus extract had no lethality in mice. However, other reports [28-30] confirmed the lethality of sea anemone extract in mice. The contradiction with Mebs et al. [24] may be due to differences in the extraction protocols. The IP LD50 of sea anemone extract for mice (29 mg. $\mathrm{kg}^{-1}$ body weight) reported in this study was within the previously reported LD50 of 700.7, $0.47,0.71$, and $108.24 \mathrm{mg} \cdot \mathrm{kg}^{-1}$ body weight (BW) for Bartholomea annulata, Stichodactyla mertensii, Stichodactyla haddoni, and Stichodactyla mertensii, respectively [2931]. These variations in LD50 may be due to the differences in species and environmental conditions that may lead to differences in chemical compositions.

The reported neurobehavioral responses observed on mice after 


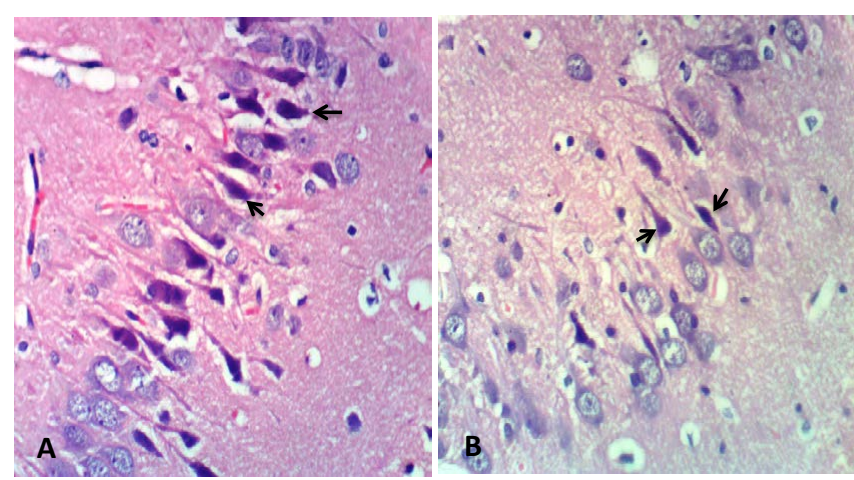

Plate 5: Hippocampal cell layer of a male albino rat following treatment with sea anemone Gyrostoma hileathus crude extract showing pyknosis and atrophy with long cytoplasmic processes of some pyramidal cells (arrow) $[400 X]$

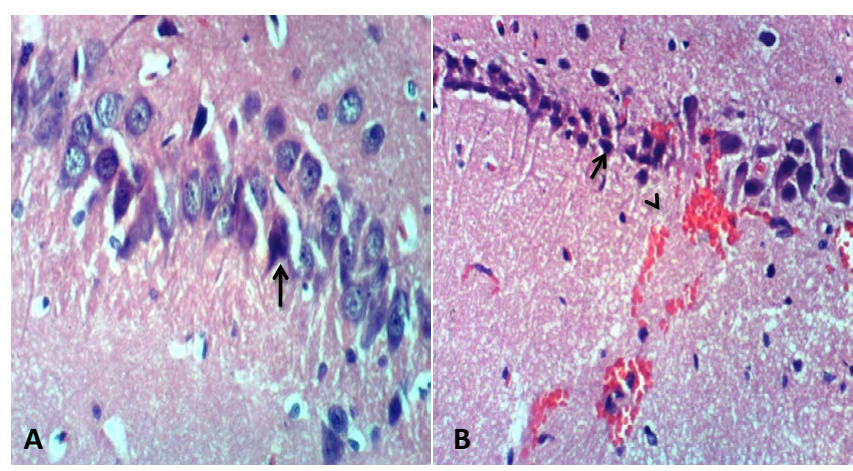

Plate 6: Hippocampal cell layer of a male albino rat following treatment with sea anemone Gyrostoma hileathus crude extract showing necrosis of some pyramidal cells (arrow) $[\mathrm{A}]$ and multiple focal hemorrhage (arrowhead) and necrosis (arrow) [B]. [200X].

IP injection of the sea anemone extract (convulsions, paralysis, and standing nape hairs) were consistent with those reported by Ramkumar et al. [32]. Different reports explain these neuronal, muscular and cardiovascular hyperexcitabilities as a result of the effect of some sea anemone polypeptides blocking neuronal sodium and potassium channels [3,33,34]; however, the effect of sea anemone extracts on the level of biogenic monoamines and their relation to GSH and related enzymes as well as the potential histopathological changes were not previously studied.

The results of the present study showed that the increase in norepinephrine (NE) dopamine (DA) and serotonin (5-HT) in the cerebellum, cerebral hemisphere, and pones plus medulla following IP injection of sea anemone extract in the rat aligns with the findings of Diochot et al. [35] who showed the enhancement of $\mathrm{Ca}^{2+}$ channel gating and catecholamine secretion as a result of sea anemone neurotoxins on voltage-gated sodium and potassium channels via transcription/ translation-dependent mechanisms and possibly nicotinic receptors. Additionally, the increase in monoamine levels observed in the current study aligned with the induction of catecholamine secretion by other marine toxin PTX reported by Yoshizumi et al. [36].

Our results suggest that the studied toxin may enhance adrenergic receptor stimulation, which may increase the biogenic monoamine levels. The most likely mechanisms of action are sympatholytic and adrenergic signaling effects, which are among the most pronounced mechanisms of the hypertension, increased blood pressure, hyperventilation and disrupted animal behavior recognized in the present investigation. This proposed mechanism is consistent with that of Yabe et al. [37] who stated that the isolated toxins from the polyp corals Clavularia sp may act as a neurotrophic factor-like agent in the cholinergic nervous system.

This mechanism is also in line with the histopathological hemorrhage findings in the cerebral hemispheres and hippocampus, which may be related to increased blood pressure. Additionally, Harris and Goonetilleke [38] reported results showing that the essential hypertension accompanying the rise in blood pressure has a significant neurogenic component and is mediated, in part, by over activity of the sympathetic nervous system. In times of high sympathetic nerve activation, adrenal medullary disorders cause very high circulating levels of catecholamine. This led to hypertension and increased blood pressure.

The histopathological changes in the studied brain areas may also be explained by the antioxidant changes observed in the current study. In the nervous system, one out of every three fatty acids (FAs) belongs to the polyunsaturated fatty acid (PUFA) group [39,40]. These PUFAs are especially vulnerable to oxidation, and many brain regions such as the cerebral cortex [41] and hippocampus [42] are highly enriched in non-heme iron. Both of these factors, specifically PUFAs and non-heme iron, increase the susceptibility of brain cells to lipid peroxidation that is catalytically involved in the production of oxygen free radicals and promotes neurodegeneration as well as functional and sensory loss in the brain tissue [43]. In the present study, the responses of cortical and hippocampal neurons were evaluated in relation to the studied toxic stress. Neurons in both areas markedly exhibited severe necrosis, atrophy, pyknosis, perivascular edema, hemorrhage and neuronal demyelination. These changes may be explained by the Mechaly et al. [44] report, which stated that sea anemone toxins affect the permeability of target cells by forming pores in their plasma membranes. Moreover, other investigators have attributed ballooning degeneration and nuclear pyknosis as prominent findings after exposure to sea anemone toxins [45]. Recently, Monroy-Estrada et al. [46] have also suggested that the sea anemone Bunodeopsis globulifera induced cytotoxicity through a different cellular mechanism that includes mitochondrial damage and alterations in the cell membrane. The histological changes could also be explained by the induction of oxidative stress. In the present study, administration of $G$. healinthus toxins significantly elevated glutathione transferase and decreased both GSH and glutathione reductase through 3 days post-treatment. One of the proposed mechanisms is glutathione reductase inhibition and glutathione transferase activation. These effects finally lead to increased generation of $\mathrm{H}_{2} \mathrm{O}_{2}$, which increases oxidative stress in the body, including neurons in the brain. In agreement with these findings, Abdel-Rahman et al. [47] found that the administration of Conus vexillum venom induces several oxidative stress biomarkers and lowers glutathione. According to Parihar et al., [48], regions such as the cortex and hippocampus are highly susceptible to oxidative damage. The present findings are in accordance with Uttara et al. [49], who reported that antioxidant enzymes and glutathione are an essential part of the cellular defense against cellular stress, including toxin exposure. Decreased activity of glutathione reductase and increased levels of glutathione transferase parallel the decrease in GSH, indicating an increase in oxidative stress in toxin-exposed animals. As reported recently by Mariottini and Pane [7], several cnidarian venoms have been found to have cytotoxic properties. In this regard, Soletti et al. [50] showed that the cytolysins EqTx-II and Bc2 from the sea anemone 
Citation: Al-Hazmi MA, Gomma MN, Waggas AS, Rawi SM (2015) Brain Biogenic Monoamines in Relation to Brain Histopathology and Plasma Glutathione Shuttle in Rat after Exposure to Sea Anemone Gyrostoma helianthus Extract. J Bioequiv Availab 7: 005-011. doi:10.4172/ jbb.1000208

Sagartia rosea potentiated cytotoxicity in human glioblastoma cells through a necrosis-like cell death. Moreover, Monroy-Estrada et al. [46] proposed that the crude extract from the sea anemone Bunodeopsis globulifera induces reactive oxygen species, which damage the cellular elements of lung cancer cells. Moreover, there is recent evidence suggesting that sea anemone toxins interact with the arylhydrocarbon receptor (AhR) [51] and activation of cytochrome P450 [52].

\section{Conclusion}

The sea anemone Gyrostoma helianthus induced the release of monoamines in brain regions, severe histopathological effects, and affected glutathione levels as well as related oxidative enzyme activity. Additional studies are needed to fully detail the neurologic effects of individual sea anemone compounds.

\section{Acknowledgements}

This project was funded by the Deanship of Scientific Research (DSR) King Abdualaziz University, KSA Project Grant No (480/130/1433), titled "Neuro bioactive extracts from some marine invertebrates inhabit the Red Sea ecosystem of Saudi Arabia."

\section{References}

1. Wang SX, Zhang XS, Guan HS, Wang W (2014) Potential anti-HPV and related cancer agents from marine resources: an overview. Mar Drugs 12: 2019-2035.

2. Wu B, Oesker V, Wiese J, Malien S, Schmaljohann R, et al. (2014) Spirocyclic drimanes from the marine fungus Stachybotrys sp. strain MF347. Mar Drugs 12: $1924-1938$

3. Andreev YA, Kozlov SA, Koshelev SG, Ivanova EA, Monastyrnaya MM, et al. (2008) Analgesic compound from sea anemone Heteractis crispa is the first polypeptide inhibitor of vanilloid receptor 1 (TRPV1). J Biol Chem 283: 2391423921.

4. Hu B, Guo W, Wang LH, Wang JG, Liu XY, et al. (2011) Purification and characterization of gigantoxin-, a new actinoporin from the sea anemone Stichodactyla gigantea. Int J Biol Sci 7: 729-739.

5. Beeton C, Pennington MW, Norton RS (2011) Analogs of the sea anemone potassium channel blocker ShK for the treatment of autoimmune diseases. Inflamm Allergy Drug Targets 10: 313-321.

6. Ravindran VS, Kannan L, Venkateshvaran K (2010) Biological activity of sea anemone proteins: I. Toxicity and histopathology. Indian J Exp Biol 48: 12251232.

7. Mariottini GL, Pane L (2013) Cytotoxic and cytolytic cnidarian venoms. A review on health implications and possible therapeutic applications. Toxins (Basel) 6: 108-151

8. Raghubir R, Mishra V, Samuel SS, Lakshmi V (2013) A potent neurotoxic effect of the methanolic extract of the parazoanthus mediated by NMDA receptors. Pharmacologia 4: 132-137.

9. Nesher N, Zlotkin E, Hochner B (2014) The sea anemone toxin AdE-1 modifies both sodium and potassium currents of rat cardiomyocytes. Biochem $\mathrm{J} 461$ : 51-59.

10. Al-Sabi A, McArthur J, Ostroumov V, French RJ (2006) Marine Toxins That Target Voltage-gated Sodium Channels. Mar Drugs 4: 157-192.

11. Prudencio $M$, Jansen-West KR, Lee WC, Gendron TF, Zhang $Y J$, et al. (2012) Misregulation of human sortilin splicing leads to the generation of a nonfunctional progranulin receptor. Proc Natl Acad Sci U S A 109: 2151021515

12. Vincent JP, Balerna M, Barhanin J, Fosset M, Lazdunski M (1980) Binding of sea anemone toxin to receptor sites associated with gating system of sodium channel in synaptic nerve endings in vitro. Proc Natl Acad Sci U S A 77: 16461650.

13. Abita JP, Chicheportiche R, Schweitz H, Lazdunski M (1977) Effects of neurotoxins (veratridine, sea anemone toxin, tetrodotoxin) on transmitter accumulation and release by nerve terminals in vitro. Biochemistry 16: 18381844.

14. Williams P, Sorribas A, Howes MJ (2011) Natural products as a source of Alzheimer's drug leads. Nat Prod Rep 28: 48-77.
15. American Association for Accreditation of Laboratory Animal Care (AAALAC) Guide for the Care and Use of Laboratory Animals. 8th Edition of the Guide NRC; The National Academic Press 20.

16. AL-Hazmi MA (2001) The effect of acute or chronic doses of nutmeg extract on behavioral locomotor activity in mice. J YTON 50: 81-89.

17. AOAC (2207) Association of Official Analytical Chemist Official methods of analysis. AOAC, Washington, DC.

18. Litchfield JT Jr, Wilcoxon F (1949) A simplified method of evaluating doseeffect experiments. J Pharmacol Exp Ther 96: 99-113.

19. Paget GE, Barnes JM (1964) Evaluation of drug activities. In: Lawrence DR Bacharach AL (Eds) Pharmacometrics. New York: Academic Press.

20. Glowinski J, Iversen LL (1966) Regional studies of catecholamines in the rat brain. I. The disposition of $[3 \mathrm{H}]$ norepinephrine, $[3 \mathrm{H}]$ dopamine and $[3 \mathrm{H}]$ dopa in various regions of the brain. J Neurochem 13: 655-669.

21. udenfriend S, Wyngaarden JB (1956) Precursors of adrenal epinephrine and norepinephrine in vivo. Biochim Biophys Acta 20: 48-52.

22. Cliarlone AE (1978) Further modification of a fluorometric method for analyzing brain amines. Microchemical J 23: 9-12.

23. Motulsky HJ (2007) Prism 5 statistics guide. San Diego CA, USA: GraphPad Software Inc.

24. Hall S, Strichartz G (2007) In: Hall S, Strichartz G (Eds) Marine Toxins: Origin, Structure, and Molecular Pharmacology. American Chemical Society, Washington DC.

25. Faulkner DJ (2001) Marine natural products. Nat Prod Rep 18: 1-49.

26. Thangaraj S, Bragadeeswaran S (2012) Assessment of biomedical and pharmacological activities of sea anemones Stichodactyla mertensii and Stichodactyla gigantea from Gulf of Mannar Biosphere Reserve, southeast coast of India. The Journal of Venomous Animals and Toxins including Tropical Diseases 18: 53-61.

27. Mebs D, Liebrich M, Reul A, Samejima Y (1983) Hemolysins and proteinase inhibitors from sea anemones of the Gulf of Aqaba. Toxicon 21: 257-264.

28. Aldeen SI, Elliott RC, Sheardown M (1981) The partial purification and bioassay of a toxin present in extracts of the sea anemone, Tealia felina (L.) $\mathrm{Br}$ J Pharmacol 72: 211-220.

29. Sanchez-Rodriguez J, Zugasti A, Santamaría A, Galván-Arzate S, SeguraPuertas $L$ (2006) Isolation, partial purification and characterization of active polypeptide from the sea anemone Bartholomea annulata. Basic Clin Pharmacol Toxicol 99: 116-121.

30. Sudharsan S, Seedevi P, Kanagarajan U, Dalvi RS, Guptha S, et al. (2013) Analgesic and neuromodulatory effects of sea anemone Stichodactyla mertensi (brandt, 1835) methanolic extract from southeast coast of India. African Journal of Pharmacy And Pharmacology 7: 2180-2200.

31. Veeruraj A, Arumugam M, Ajithkumar T, Balasubramanian T (2007) Isolation and biological properties of neurotoxin from sea anemone (Stichodactyla mertensii, S. haddoni). The Internet Journal of Toxicology 5.

32. Ramkumar S, Sudhagar AS, Venkateshvaran K (2012) Bioactivity of venom extracted from the sea anemone Anthopleura asiatica (Cnidaria: Anthozoa) Toxicity and histopathological studies. International Journal of Fisheries and Aquaculture 4: 71-76.

33. Yamaguchi Y, Hasegawa Y, Honma T, Nagashima Y, Shiomi K (2010) Screening and cDNA cloning of Kv1 potassium channel toxins in sea anemones. Mar Drugs 8: 2893-2905.

34. Sabogal-Arango A, Barreto GE, Ramírez-Sánchez D, González-Mendoza J, Barreto V, et al. (2014) Computational Insights of the Interaction among Sea Anemones Neurotoxins and Kv1.3 Channel. Bioinform Biol Insights 8: 73-81.

35. Diochot S, Richard S, Baldy-Moulinier M, Nargeot J, Valmier J (1995) Dihydropyridines, phenylalkylamines and benzothiazepines block N-, P/Q- and R-type calcium currents. Pflugers Arch 431: 10-19.

36. Yoshizumi M, Houchi H, Ishimura Y, Masuda Y, Morita K, et al. (1991) Mechanism of palytoxin-induced $\mathrm{Na}+$ influx into cultured bovine adrenal chromaffin cells: possible involvement of $\mathrm{Na}+/ \mathrm{H}+$ exchange system. Neurosc Lett 130: 103-106.

37. Yabe T, Yamada H, Shimomura M, Miyaoka H, Yamada Y (2000) Induction 
Citation: Al-Hazmi MA, Gomma MN, Waggas AS, Rawi SM (2015) Brain Biogenic Monoamines in Relation to Brain Histopathology and Plasma Glutathione Shuttle in Rat after Exposure to Sea Anemone Gyrostoma helianthus Extract. J Bioequiv Availab 7: 005-011. doi:10.4172/ jbb.1000208

of choline acetyltransferase activity in cholinergic neurons by stolonidiol: structure-activity relationship. J Nat Prod 63: 433-435.

38. Harris JB, Goonetilleke A (2004) Animal poisons and the nervous system: what the neurologist needs to know. J Neurol Neurosurg Psychiatry 75 Suppl 3: iii4046.

39. Sastry PS (1985) Lipids of nervous tissue: composition and metabolism. Prog Lipid Res 24: 69-176.

40. Logan AC, Frsh ND (2003) Neurobehavioral aspects of omega-3 fatty acids: Possible mechanisms and therapeutic value in major depression. Altern Med Rev 8: 410-425.

41. Yoneyama-Sarnecky T, Olivas AD, Azari S, Ferriero DM, Manvelyan HM, et al. (2010) Heme oxygenase-2 modulates early pathogenesis after traumatic injury to the immature brain. Dev Neurosci 32: 81-90.

42. Sadrzadeh SM, Saffari Y (2004) Iron and brain disorders. Am J Clin Pathol 121 Suppl: S64-70.

43. Singh RP, Sharad S, Kapur S (2004) Free Radicals and Oxidative Stress in Neurodegenerative Diseases: Relevance of Dietary Antioxidants. JIACM 5: 218-225

44. Mechaly AE, Bellomio A, Gil-Cartón D, Morante K, Valle M, et al. (2011) Structural insights into the oligomerization and architecture of eukaryotic membrane pore-forming toxins. Structure 19: 181-191.

45. Letot B, Piérard-Franchimont C, Piérard GE (1990) Acute reactions to coelenterates. Dermatologica 180: 224-227.

46. Monroy-Estrada HI, Chirino YI, Soria-Mercado IE, Sánchez-Rodríguez J1
(2013) Toxins from the Caribbean sea anemone Bunodeopsis globulifera increase cisplatin-induced cytotoxicity of lung adenocarcinoma cells. J Venom Anim Toxins Incl Trop Dis 19: 12

47. Abdel-Rahman MA, Abdel-Nabi IM, El-Naggar MS, Abbas OA, Strong PN (2013) Conus vexillum venom induces oxidative stress in Ehrlich's ascites carcinoma cells: an insight into the mechanism of induction. J Venom Anim Toxins Incl Trop Dis 19: 10.

48. Parihar MS, Chaudhary M, Shetty R, Hemnani T (2004) Susceptibility of hippocampus and cerebral cortex to oxidative damage in streptozotocin treated mice: prevention by extracts of Withania somnifera and Aloe vera. J Clin Neurosci 11: 397-402.

49. Uttara B, Singh AV, Zamboni P, Mahajan RT (2009) Oxidative stress and neurodegenerative diseases: a review of upstream and downstream antioxidant therapeutic options. Curr Neuropharmacol 7: 65-74.

50. Soletti RC, de Faria GP, Vernal J, Terenzi H, Anderluh G, et al. (2008) Potentiation of anticancer-drug cytotoxicity by sea anemone pore-forming proteins in human glioblastoma cells. Anticancer Drugs 19: 517-525.

51. Reitzel AM, Passamaneck YJ, Karchner SI, Franks DG, Martindale MQ, et al. (2014) Aryl hydrocarbon receptor (AHR) in the cnidarian Nematostella vectensis: comparative expression, protein interactions, and ligand binding Dev Genes Evol 224: 13-24.

52. Chi V, Pennington MW, Norton RS, Tarcha EJ, Londono LM, et al. (2012) Development of a sea anemone toxin as an immunomodulator for therapy of autoimmune diseases. Toxicon 59: 529-546. 